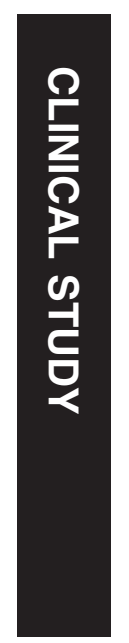

\title{
Comparison of new motorized injector vs manual injector for implantation of foldable intraocular lenses on wound integrity: an ASOCT study
}

S Khokhar, R Sharma, B Patil, N Aron and S Gupta

\section{Abstract}

Purpose To compare intraocular lens implantation using a motorized injector $v s$ standard manual injector through a $2.2-\mathrm{mm}$ clear corneal incision.

Methods Patients underwent standard phacoemulsification using a 2.2-mm clear corneal incision. Hydrophobic acrylic aspheric intraocular lens (Acrysof SN60WF intraocular lens (IOL)) was inserted using D cartridge with manual monarch injector or autosert motorized injector. IOL safety, final incision size and wound integrity in terms of anterior and posterior wound gape, and descemet's membrane detachment were compared between the two groups at post-operative day 1 and at 1 month using Anterior Segment Optical Coherence Tomography.

Results The study recruited 32 patients in the group I (manual injector) and 30 patients in group II (motorized injector). In group I, the final incision after IOL insertion increased by $0.12 \mathrm{~mm}$ (95\% CI: $0.134-0.106)$ $(P<0.0001)$, which was seen in $100 \%$ of the patients. In group II, the incision enlarged by 0.01 (95\% CI: $0.021-0.0 .001)(P=0.07)$ and was seen in only $6.67 \%$ of the cases. IOL nicks were seen in $9.37 \%$ of the cases in group I only. Although the incidence of descemet's membrane detachment and anterior wound gape was similar for both groups, posterior wound gape was seen more often with the manual injector in the immediate postoperative period. $(P=\mathbf{0 . 0 1 8})$ Conclusion The motorized insertion system was gentle and safe for the IOLs with lesser incidence of IOL nicks. Regarding wound safety, it caused significantly less incision enlargement and better posterior wound integrity.

Eye (2014) 28, 1174-1178; doi:10.1038/eye.2014.162; published online 18 July 2014

Introduction

Clear corneal incision phacoemulsification is the preferred practice for cataract removal in the present scenario. ${ }^{1}$ Over the past few decades, there is a trend toward reduction of incision size. ${ }^{2,3}$ Smaller incisions offer faster rehabilitation, lesser astigmatism, lesser inflammation, and fewer chances of wound leak and post-operative endophthalmitis. ${ }^{4-7}$

Autosert (Alcon Laboratories, Inc., Fort Worth, TX, USA) is a new motorized intraocular lens (IOL) injector system that has been launched recently in India. There are safety reports available with the use of Autosert for IOL implantation. ${ }^{8}$ It is easy to use and was found to cause less incision enlargement during IOL implantation by Allen et $a l^{8}$ We compared this device with the manual Monarch injector, provided by the same manufacturer, with respect to IOL safety, incision size, and wound integrity using Anterior Segment Optical Coherence Tomography (ASOCT; Visante; Carl Zeiss Meditec, Inc., Dublin, CA, USA).

Materials and methods

This was a prospective, randomized study conducted at our tertiary care centre. Patients were randomized using a list of computer-generated random numbers at the time of deciding the surgical date. Consecutive patients who had no
23 May 2014

Published online: 18 July 2014 
ocular pathology other than cataract and planned for standard phacoemulsification surgery were recruited in the study. All preoperative investigations for cataract surgery were done by a single, experienced observer.

Informed consent was taken and patients received standard $2.2 \mathrm{~mm}$ phacoemulsification by a single surgeon and on a single machine. They were randomized to receive IOL implantation using manual Monarch injector (group I) or motorized Autosert injector (group II) with a D cartridge for hydrophobic acrylic aspheric intraocular lens (Acrysof SN60WF IOL, Alcon Laboratories, Inc.). Incision width was measured before and immediately after IOL implantation in both the groups using incision gauge (Appasamy incision Gauge model AA2102, Appasamy Associates, Arumbakkam, Chennai, India) (Figure 1). Patients in whom the incision size enlarged by more than $2.2 \mathrm{~mm}$ after irrigation-aspiration and before IOL was implanted were excluded from the study. Presence of any IOL nicks or scratches if observed during IOL insertion were noted and documented. ASOCT was done on first post-operative day and at 1 month by a randomization blind examiner.

\section{Surgical technique}

All surgeries were performed by a single experienced surgeon (SK) in the same operating room for phacoemulsification. Following an aseptic technique, a clear corneal incision was made temporally using a 2.2-mm metal trapezoidal keratome (ClearCut slit knife, single bevel; Alcon Laboratories, Inc.) under topical anesthesia. A side port incision was created using a microvitreoretinal blade (Alcon Laboratories, Inc.). Cohesive viscoelastic was injected to fill the anterior chamber and circular continuous capsulorrhexis was performed using capsulotomy needle. Cortical cleaving hydrodissection was done and nucleus was emulsified using horizontal chop technique. Phacoemulsification in all cases was done using torsional phaco with the Infiniti Vision System (Alcon Laboratories, Inc.) with a 0.9-mm Kelman miniflare tip (Alcon Laboratories, Inc.) and $0.9 \mathrm{~mm}$ Ultrasleeve (Alcon Laboratories, Inc.). Irrigationaspiration of cortical material was done using Intrepid silicone-sleeved co-axial system (Alcon Laboratories, Inc.). The incision width was measured after filling the anterior chamber and the bag with a cohesive viscoelastic. Patients with incision $>2.2 \mathrm{~mm}$ before IOL implantation were excluded from the study. Hydrophobic acrylic aspheric intraocular lens (Acrysof SN60WF IOL) implantation was done using a D cartridge with a Monarch manual injector in one group and Autosert motorized injector in the other group. Proper IOL loading was done by the same experienced surgeon (SK) with the haptics folded over the optic.
Wound-assisted IOL insertion was done in both groups. Autosert was used with an initial velocity of $2.5 \mathrm{~mm} / \mathrm{s}$ followed by a pause of $0.5 \mathrm{~s}$ and then a final velocity of $2.5 \mathrm{~mm} / \mathrm{s}$. Final positioning of the IOL in bag was done using the plunger end. The incision width was again measured immediately after IOL implantation and recorded. Finally the viscoelastic was removed using irrigation-aspiration. The IOL status was checked for the presence of any nicks or scratches and final position was noted. Incisions were hydrated and checked for leakage after which antibiotics and steroids were instilled.

ASOCT was done for all the patients for main $2.2 \mathrm{~mm}$ incision using 'Enhanced high resolution corneal protocol' on post-operative day 1 and day 30 by a randomization blind investigator. Presence and extent of wound gape was noted for both the groups. Extent of gape or nonapposition of the incision was observed on ASOCT. Extent of descemet membrane detachment and posterior wound retraction, if any, were also assessed. Posterior wound retraction was defined as a step-off or recession of the limbal edge of the posterior wound surface. ${ }^{9}$

Statistical analysis was done using SPSS software version 15.0 (SPSS, Inc., Chicago, IL, USA) and $P<0.05$ was considered significant.

\section{Results}

Sixty-two patients were included in the study, 32 in the group with manual injector (group I) and 30 in the group with Autosert motorized injector (group II). The difference between the mean age and mean IOL power in either group was comparable (Table 1). On assessing IOL safety, small nicks were seen in three $(9.37 \%)$ cases in IOL periphery in group I but none were seen in group II (Figure 2). Only those patients who had incision size $2.2 \mathrm{~mm}$ after irrigation-aspiration were considered. In group I, final incision after IOL insertion increased to $2.3 \mathrm{~mm}$ in 27 eyes and in the remaining 5 eyes it increased to $2.4 \mathrm{~mm}$, while in Autosert group, 28 of the incisions remained at $2.2 \mathrm{~mm}$ after insertion and only 2 increased to $2.3 \mathrm{~mm}$. ( $P<0.0001$; Fisher's Exact test; Table 2).

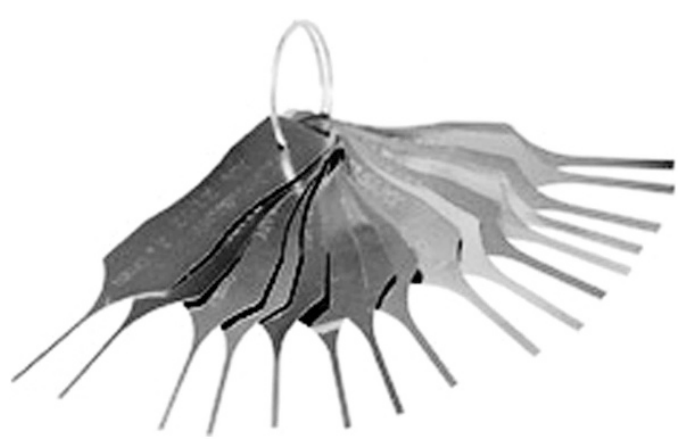

Figure 1 Incision gauges used for measuring incision size. 
Table 1 Comparison of age and intraocular lens power between manual injector group and motorized injector group

\begin{tabular}{lccc}
\hline & Group I: manual injector group $(\mathrm{n}=32)$ & Group II: motorized injector group $(\mathrm{n}=30)$ & $\mathrm{P}$ \\
\hline Mean age \pm SD (range; years) & $61.47 \pm 5.31$ years (50-70 years) & $60.83 \pm 6.15$ years (50-70 years) & 0.664 \\
Mean IOL power \pm SD (range; dioptre) & $23.33 \pm 0.97 \mathrm{D}(21.5-25 \mathrm{D})$ & $22.8 \pm 1.13 \mathrm{D}(20-25 \mathrm{D})$ & 0.052 \\
\hline
\end{tabular}

Abbreviation: IOL, intraocular lens.

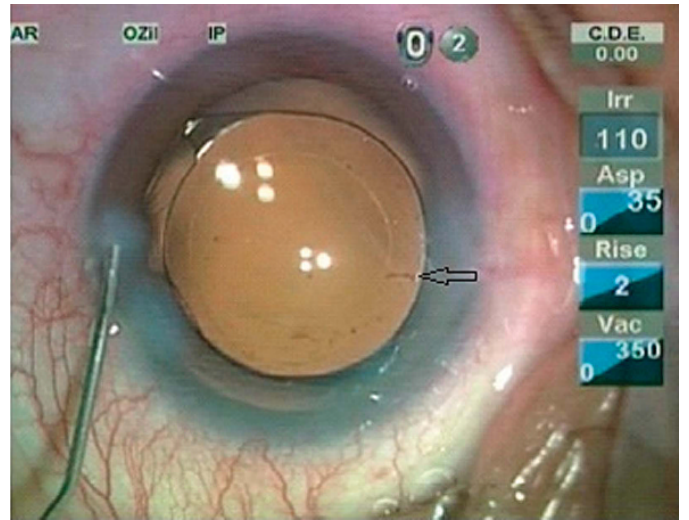

Figure 2 Arrow showing IOL nick in periphery in a patient in which IOL implantation was done using manual injector.

Localized descemet membrane detachment was seen in $14(43.75 \%)$ eyes in manual group and in $7(23.33 \%)$ eyes in group II $(P=0.09)$ using ASOCT on postoperative day 1 (Figures $3 a$ and b; Table 2). However, on follow up at 1 month, none of the patients had descemet detachment. No anterior wound gape was seen in either of the groups. Posterior wound gape was seen in 16 $(50 \%)$ patients in manual group and $6(20 \%)$ in the motorized group at day $1(P=0.018)$; however, none of the patients had evidence of gape at 1 month follow-up (Figures $3 \mathrm{~d}$ and e). None of the patients had posterior wound gape, which extended in size by more than onefourth of the total incision length. Posterior wound retraction was seen in only one patient in the manual group at 1 month (Figure 3c; Table 2).

\section{Discussion}

There is an increasing trend toward smaller incision size in phacoemulsification along with greater preference for square-edged intraocular lenses to decrease the incidence of posterior capsular opacification. This requires lenses to be inserted through smaller incisions and smaller bore cartridges. For IOL implantation through incisions $\leq 2.2 \mathrm{~mm}$, injector systems are safer as compared with forceps. However an ideal injector system still eludes the medical fraternity. With available reports on Autosert, ${ }^{8}$ we tried to find the IOL safety, changes in incision size after the IOL insertion, and wound integrity on ASOCT comparing manual and motorized injector systems.
Phacoemulsification with IOL implantation may lead to an increase in original incision size occurring at various steps. ${ }^{10,11}$ Maximum incision stretch has been shown to occur during IOL implantation. ${ }^{11}$ Steinert and Deacon ${ }^{12}$ reported that an irreversible increase in incision size follows phacoemulsification surgery due to initial stretch-related incision tearing. Various factors have been seen to affect the amount of incision enlargement, including dioptric power of IOL, ${ }^{13}$ type of IOL, ${ }^{14}$ type of keratome, ${ }^{15}$ and speed of IOL insertion. ${ }^{16}$ Contrarily, Kohnen et al found that IOL power, material, and shape of cartridge do not affect incision size. ${ }^{17}$ According to them, width of injector is the only factor which affects incision enlargement significantly. However, most of these studies have been done on incisions of size $>2.5 \mathrm{~mm} \cdot{ }^{12,13,17}$ In our study, we compared incision enlargement with $2.2 \mathrm{~mm}$ incision and found the incision to enlarge in $100 \%$ of the cases, when using D cartridge with manual injector. Our results approximate that of Osher ${ }^{18}$ who recorded $100 \%$ enlargement with 2.2-mm incision size. However they used a C cartridge and hence, the enlargement was not due to IOL implantation alone. Similarly, Espiritu and Bernardo ${ }^{11}$ used $2.2 \mathrm{~mm}$ incision with D cartridge using Monarch III manual injector and found enlargement in $93.5 \%$ of the eyes. The mean enlargement in incision size after cortical aspiration to after IOL implantation in their study was $0.046 \mathrm{~mm}$, which is a little less than ours $(0.12 \mathrm{~mm})$. We also compared the difference in final incision sizes with D cartridge and Autosert and found lesser incision enlargement with Autosert, which was statistically significant; results similar to those reported by Allen et al. ${ }^{8}$ Forcing implantation of IOL through incision of smaller than adequate size may lead to corneal damage manifesting as descemet's tears, irregularities, distortions, and improper wound healing. The ideal incision size for use of $\mathrm{D}$ cartridge has been observed by Espiritu and Bernardo ${ }^{11}$ to be $2.3 \mathrm{~mm}$ with woundassisted implantation of IOL. Our study also favors this observation as in $84.4 \%$ of patients the incision enlarged to $2.3 \mathrm{~mm}$ with the same technique. In addition, we found no enlargement of incision in cases with Autosertassisted implantation in $93.33 \%$ of the eyes. Thus $2.2 \mathrm{~mm}$ is an adequate-sized incision for IOL implantation using Autosert, when used in conjunction with D cartridge.

We have also found IOL nicks in the periphery in group I, when using D cartridge. This has not been 
Table 2 Comparison of incision size, IOL nicks, and wound characteristics on ASOCT between manual injector group and motorized injector group

\begin{tabular}{|c|c|c|c|}
\hline Post-operative day & Group I: manual injector $(\mathrm{n}=32)$ & Group II: motorized injector $(\mathrm{n}=30)$ & $\mathrm{P}$ \\
\hline Final incision size: mean \pm SD (mm) & $2.32 \pm 0.04 \mathrm{~mm}(2.3-2.4 \mathrm{~mm})$ & $2.21 \pm 0.03 \mathrm{~mm}(2.2-2.3 \mathrm{~mm})$ & $<0.0005$ \\
\hline Change from baseline in $\mathrm{mm}(2.2 \mathrm{~mm})$ & 0.12 (95\% CI: 0.134-0.106) $(P<0.0001)$ & 0.01(95\% CI: $0.021-0.0 .001)(P=0.07)$ & NA \\
\hline Incision enlargement & 32 & 2 & 0.0001 \\
\hline Incision size: $2.3 \mathrm{~mm}(\%)$ & $27(84.4 \%)$ & $2(6.67 \%)$ & 0.0001 \\
\hline Incision size: 2.4 mm (\%) & $5(15.6 \%)$ & 0 & 0.053 \\
\hline Number in which IOL nick was present (\%) & $3(9.37 \%)$ & 0 & 0.260 \\
\hline \multicolumn{4}{|l|}{ Anterior gape } \\
\hline Day 1 & 0 & 0 & NA \\
\hline Day 30 & 0 & 0 & NA \\
\hline \multicolumn{4}{|l|}{ Posterior gape } \\
\hline Day 1 & $16(50 \%)$ & $6(20 \%)$ & 0.018 \\
\hline Day 30 & 0 & 0 & NA \\
\hline \multicolumn{4}{|l|}{ Descemet membrane detachment } \\
\hline Day 1 & $14(43.75 \%)$ & $7(23.33 \%)$ & 0.090 \\
\hline Day 30 & 0 & 0 & NA \\
\hline \multicolumn{4}{|l|}{ Posterior wound retraction } \\
\hline Day 1 & 0 & 0 & NA \\
\hline Day 30 & $1(3.125 \%)$ & 0 & 1 \\
\hline
\end{tabular}

Abbreviations: ASOCT, anterior segment optical coherence tomography; CI, confidence interval; IOL, intraocular lens; NA, not applicable; SD, standard deviation. Bold values indicate a significant $P$ value.

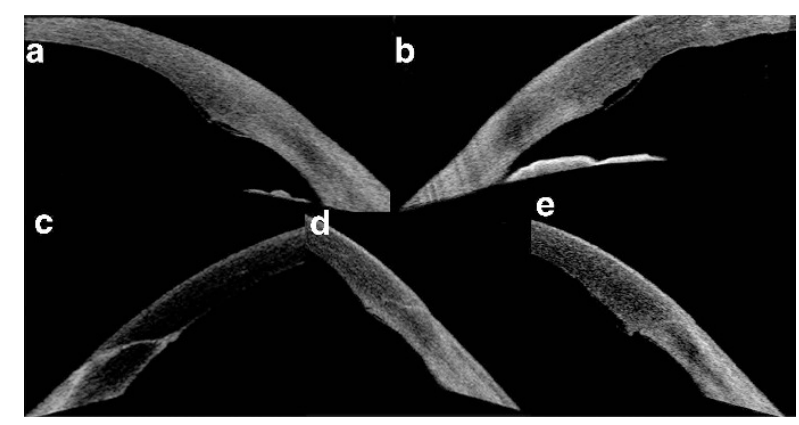

Figure 3 (a) ASOCT image showing descemet membrane detachment in a patient in the manual injector group on day 1 . (b) ASOCT image showing descemet membrane detachment in a patient in the motorized injector group on day 1. (c) ASOCT image showing posterior wound retraction in a patient in the manual injector group at 1 month. (d) ASOCT image showing posterior gape in a patient in the manual injector group on day 1. (e) ASOCT image showing posterior gape in a patient in the motorized injector group on day 1 . Note that the incision architecture is arcuate thus imparting greater wound strength.

reported previously in literature. As both hands are engaged when using manual injector and the eye usually rolls nasally during insertion through temporal incision under topical anesthesia, this causes more force to be applied on the wound as well as during the final plunge of the IOL. This can sometimes cause over-riding of the plunger onto the folded IOL inside the cartridge resulting in IOL nicks and associated wound distortion.
ASOCT is a useful investigative modality for determination of wound morphology and evolution over time when compared with clinical appreciation on slit lamp biomicroscopy. Though ASOCT-assisted in vivo evaluation of wound architecture in patients undergoing phacoemulsification has been done previously, ${ }^{19-23}$ we used ASOCT to compare manual vs the new motorized injector and to assess its safety, which has not been reported previously. No differences could be elicited between the two groups with respect to descemet's membrane detachment, anterior wound gape, and posterior gape at 1 month. None of our eyes developed epithelial gape. This may be because a two-step clear corneal incision is arcuate in configuration (Figures 3a-e), rather than linear, and hence is more stable. ${ }^{19}$ Lyles et $a l^{20}$ similarly reported preservation of epithelial integrity on first post-operative day in their series. The presence of transient descemet membrane detachment and endothelial gape was elicited on first post-operative day in both groups. Torres et $a l^{21}$ reported similar wound distortion using a $3.2 \mathrm{~mm}$ incision with a manual injector. On serial ASOCT examination at 1 month, all 22 eyes showed resolution of posterior wound gape, a trend similar to that seen by Chee $e t a l^{23}$ and Dupont-Monod et al. ${ }^{22}$ They also reported that the posterior gape did not exceed by $>25 \%$ of total incision length in their series, an observation similar to ours. Posterior wound gape has been shown to correlate to greater contrast enhancement 
at wound site, especially in the first $24 \mathrm{~h}$, thus predisposing these eyes for endophthalmitis. ${ }^{24}$ Thus, Autosert may provide safer wound architecture in the immediate post-operative period, a time most crucial for development of endophthalmitis, in comparison to manual IOL injection.

Though a small sample size and the use of incision gauges with minimum calibration up to $0.1 \mathrm{~mm}$ resolution comprises our limitations, an in vivo comparison of wound architecture between the two groups, which has not been done previously, brings forth novel observations. We conclude that use of D cartridge with Autosert motorized injector is safe as far as wound morphology and IOL insertion is concerned; it causes lesser incision enlargement, fewer IOL nicks, and is easier to use.

\section{Summary}

What was known before

- Incision may increase in size after autosert IOL implantation was measured using guage. ASOCT may show wound gape, descemets detachment, and wound override after phacoemulsification. ASOCT comparative study between manual and motorized IOL injection to study wound healing has not been done.

\section{What this study adds}

- The motorized system is gentle and safe for the IOLs causing less IOL-scratches

- Wound integrity was better maintained as seen by ASOCT.

\section{Conflict of interest}

The authors declare no conflict of interest.

\section{References}

1 Leaming DV. Practice styles and preferences of ASCRS members-survey 2001. J Cataract Refract Surg 2002; 28: $1681-1688$

2 Leaming DV. Practice styles and preferences of ASCRS members-1985 survey. J Cataract Refract Surg 1986; 12 380-384.

3 Leaming DV. Snapshots [guest editorial]. J Cataract Refract Surg 2006; 32: 1401-1402.

4 Kohnen T, Dick B, Jacobi KW. Comparison of the induced astigmatism after temporal clear corneal tunnel incision of different sizes. J Cataract Refract Surg 1995; 21: 417-424.

5 Masket S, Wang L, Belani S. Induced astigmatism with 2.2- and 3.0-mm coaxial phacoemulsification incisions. J Refract Surg 2009; 25: 21-24.

6 Hayashi K, Yoshida M, Hayashi H. Postoperative corneal shape changes: microincision versus small-incision coaxial cataract surgery. J Cataract Refract Surg 2009; 35: 233-239.

7 Elkady B, Pinero D, Alio JL. Corneal incision quality: microincision cataract surgery versus microcoaxial phacoemulsification. J Cataract Refract Surg 2009; 35: 466-474.
8 Allen D, Habib M, Steel D. Final incision size after implantation of a hydrophobic acrylic aspheric intraocular lens: new motorized injector versus standard manual injector. J Cataract Refract Surg 2012; 38: 249-255.

9 Wang L, Dixit L, Weikert MP, Jenkins RB, Koch DD. Healing changes in clear corneal cataract incisions evaluated using Fourier-domain optical coherence tomography. J Cataract Refract Surg 2012; 38: 660-665.

10 Kohnen T, Klaproth OK. Incision sizes before and after implantation of SN60WF intraocular lenses using the Monarch injector system with C and D cartridges. J Cataract Refract Surg 2008; 34: 1748-1753.

11 Espiritu CR, Bernardo Jr JP. Incision sizes at different stages of phacoemulsification with foldable intraocular lens implantation. J Cataract Refract Surg 2009; 35: 2115-2120.

12 Steinert RF, Deacon J. Enlargement of incision width during phacoemulsification and folded intraocular lens implant surgery. Ophthalmology 1996; 103: 220-225.

13 Moreno-Montanes J, Garcia-Layana A, Aliseda D, Munuera JM. Variation in clear cornea incision size after phacoemulsification and foldable lens implantation. J Cataract Refract Surg 1998; 24: 931-934.

14 Moreno-Montañés J, Maldonado MJ, García-Layana A, Aliseda D, Munuera JM. Final clear corneal incision size for AcrySof intraocular lenses. J Cataract Refract Surg 1999; 25: 959-963.

15 Radner W, Menapace R, Zehetmayer M, Mallinger R. Ultrastructure of clear corneal incisions. Part I: effect of keratomes and incision width on corneal trauma after lens implantation. J Cataract Refract Surg 1998; 24: 487-492.

16 Ouchi M. Effect of intraocular lens insertion speed on surgical wound structure. J Cataract Refract Surg 2012; 38: 1771-1776.

17 Kohnen $\mathrm{T}$, Kasper T. Incision sizes before and after implantation of 6-mm optic foldable intraocular lenses using Monarch and Unfolder injector systems. Ophthalmology 2005; 112: 58-66.

18 Osher RH. Microcoaxial phacoemulsification. Part 2: clinical study. J Cataract Refract Surg 2007; 33: 408-412.

19 Fine IH, Hoffman RS, Packer M. Profile of clear corneal cataract incisions demonstrated by ocular coherence tomography. J Cataract Refract Surg 2007; 33: 94-97.

20 Lyles GW, Cohen KL, Lam D. OCT-documented incision features and natural history of clear corneal incisions used for bimanual microincision cataract surgery. Cornea 2011; 30: 681-686.

21 Torres LF, Saez-Espinola F, Colina JM, Retchkiman M, Patel MR, Agurto R et al. In vivo architectural analysis of $3.2 \mathrm{~mm}$ clear corneal incisions for phacoemulsification using optical coherence tomography. J Cataract Refract Surg 2006; 32: $1820-1826$.

22 Dupont-Monod S, Labbe A, Fayol N, Chassignol A, Bourges JL, Baudouin C. In vivo architectural analysis of clear corneal incisions using anterior segment optical coherence tomography. J Cataract Refract Surg 2009; 35: 444-450.

23 Chee SP, Ti SE, Lim L, Chan AS, Jap A. Anterior segment optical coherence tomography evaluation of the integrity of clear corneal incisions: a comparison between 2.2-mm and 2.65-mm main incisions. Am J Ophthalmol 2010; 149: 768-776.

24 Gupta PK, Ehlers JP, Kim T. Evaluation of clear corneal wound dynamics with contrast-enhanced spectral-domain optical coherence tomography. Ophthalmic Surg Lasers Imaging 2012; 43: 222-228. 